\title{
The Role of Vitamin D in the Pathogenesis of Adolescent Idiopathic Scoliosis
}

\author{
Shu-Yan $\mathrm{Ng}^{1}$, Josette Bettany-Saltikov ${ }^{2}$, Irene Yuen Kwan Cheung ${ }^{1}$, Karen Kar Yin Chan ${ }^{3}$ \\ ${ }^{1}$ Wanchi Chiropractic Clinic, Hong Kong \\ ${ }^{2}$ Institute of Health and Social Care, Teesside University, Middlesbrough, UK \\ ${ }^{3}$ Grace Act Chiropractic Centre Ltd., Hong Kong
}

\begin{abstract}
Several theories have been proposed to explain the etiology of adolescent idiopathic scoliosis (AIS) until present. However, limited data are available regarding the impact of vitamin D insufficiency or deficiency on scoliosis. Previous studies have shown that vitamin $D$ deficiency and insufficiency are prevalent in adolescents, including AIS patients. A series of studies conducted in Hong Kong have shown that as many as 30\% of these patients have osteopenia. The 25-hydroxyvitamin D3 level has been found to positively correlate with bone mineral density (BMD) in healthy adolescents and negatively with Cobb angle in AIS patients; therefore, vitamin $D$ deficiency is believed to play a role in AIS pathogenesis. This study attempts to review the relevant literature on AIS etiology to examine the association of vitamin $D$ and various current theories. Our review suggested that vitamin $D$ deficiency is associated with several current etiological theories of AIS. We postulate that vitamin D deficiency and/or insufficiency affects AIS development by its effect on the regulation of fibrosis, postural control, and BMD. Subclinical deficiency of vitamin K2, a fat-soluble vitamin, is also prevalent in adolescents; therefore, it is possible that the high prevalence of vitamin $\mathrm{D}$ deficiency is related to decreased fat intake. Further studies are required to elucidate the possible role of vitamin $\mathrm{D}$ in the pathogenesis and clinical management of AIS.
\end{abstract}

Keywords: Bone density; Vitamin D; Vitamin K; Scoliosis

\section{Introduction}

Adolescent idiopathic scoliosis (AIS) affects 0.47\%-11.1\% of the general population [1]. As the name suggests, the cause of the condition remains unclear. Several theories have been proposed, including genetic, neuro-developmental abnormalities, motor control and motor-sensory integration dysfunctions, vestibular and proprioceptive disorders, biomechanical growth modulation, uncoupled spinal neuro-osseous growth, thoracospinal concept, systemic and metabolic disorders [2], and decreased bone density [3-5] (Table 1).

Recently, Schlösser et al. [6] in 2014 performed a structured review of the literature regarding all the proposed and diverse etiologies proposed for the causes of AIS. They found that of all the theories, only those related to impaired gait control and decreased bone mineral density (BMD) had a moderate strength of evidence (Table 2). Other theories, including those of different volume of the cerebellar regions, asymmetric somatosensory evoked potentials, reduced trunk strength, decreased body weight, increased breast asymmetry, and impaired bone quality

Received Dec 18, 2017; Revised Apr 12, 2018; Accepted May 22, 2018

Corresponding author: Irene Y. K. Cheung

Wanchai Chiropractic Clinic, 11/fl China Hong Kong Bldg, 8 Hennessy Road, Wanchai, Hong Kong

Tel: +852-39983028, Fax: +852-39983222, E-mail: irenecheungyk@gmail.com 
Table 1. The different proposed theories on the aetiologies of adolescent idiopathic scoliosis

\begin{tabular}{|c|c|}
\hline Hereditary factors & Content \\
\hline Biomechanical factors & $\begin{array}{l}\text { Asymmetric stiffness of inter-trans- } \\
\text { verse ligaments } \\
\text { Relative anterior spinal growth } \\
\text { Asynchronous spinal neuro-osseous } \\
\text { growth } \\
\text { Thoracospinal concept } \\
\text { Dorsal shear forces and axial rotation } \\
\text { instability } \\
\text { Flexural-torsional buckling } \\
\text { Intervertebral disc disorder } \\
\text { Deforming } 3 \text { joint complex hypothesis }\end{array}$ \\
\hline Neurological disorders & $\begin{array}{l}\text { Motor control disorder } \\
\text { Sensorimotor integration disorder } \\
\text { Sensory integration disorder } \\
\text { Vestibular disorder } \\
\text { Body spatial orientation disorder } \\
\text { Neuro-developmental disorder }\end{array}$ \\
\hline $\begin{array}{l}\text { Systemic and metabolic } \\
\text { disorders }\end{array}$ & $\begin{array}{l}\text { Platelet calmodulin } \\
\text { Melatonin } \\
\text { Melatonin-signaling defect } \\
\text { Osteopontin and soluble CD44 } \\
\text { Oestrogens } \\
\text { Leptin } \\
\text { Osteopenia } \\
\text { Vitamin D deficiency or insufficiency }\end{array}$ \\
\hline Developmental instability & - \\
\hline $\begin{array}{l}\text { Intrinsic growth plate hy- } \\
\text { pothesis }\end{array}$ & - \\
\hline Double neuro-osseous theory & - \\
\hline
\end{tabular}

were only supported by weak evidence [6].

Considering that vitamin $\mathrm{D}$ may reportedly play a role in the cerebral process of postural balance [7] and that serum vitamin D level is positively correlated with the BMD of the hip [8,9] and negatively with the Cobb angle [10], vitamin D insufficiency or deficiency is speculated to influence AIS etiopathogenesis (Table 3).

In this study, we attempted to determine whether there is an association between vitamin $\mathrm{D}$ and the different current and relevant theories regarding AIS. We also assessed the impact of vitamin D deficiency or insufficiency on AIS development.

\section{Genetics and Vitamin D}

It has long been known that hereditary factors play a role in the etiology of idiopathic scoliosis (IS) [11-13]. In the previous 10-20 years, genetic association studies and genome-wide association studies (GWAS) have been used to identify single nucleotide polymorphism (SNP), namely, the variants of genes associated with AIS [14]. A genetic association study examines if one or more genes within a population co-occur with a disease more often than expected by chance occurrence, while GWAS involve the examination of the entire genome [15].

While several GWAS have identified different SNPs associated with AIS [16], they did not consider the specific

Table 2. Level of evidence of different theories on aetiologies of AIS

$\begin{array}{ll}\text { Evidence associated with AIS } \\ \text { Moderate evidence } & \begin{array}{l}\text { Neuromuscular: impaired gait control } \\ \text { Metabolic: decreased bone mineral density }\end{array} \\ \text { Weak evidence } & \begin{array}{l}\text { Neuromuscular: different vestibular morphology; decreased cortical thickness; different volume of cerebellar regions; } \\ \text { asymmetric somatosensory evoked potentials; reduced trunk muscle strength } \\ \text { Arthropometric: increased corrected body height; reduced body weight; increased breast asymmetry } \\ \text { Metabolic: impaired bone quality }\end{array}\end{array}$

Modified from Schlosser et al. PLoS One 2014;9:e97461 [6].

AIS, adolescent idiopathic scoliosis.

Table 3. Definition of vitamin D insufficiency, deficiency and sufficiency varies with experts

\begin{tabular}{lll}
$\begin{array}{ll}\text { Organization } \\
\text { American Academy of Pediatrics }\end{array}$ & \multicolumn{1}{c}{ Vitamin D level } \\
& Deficiency & $<20 \mathrm{ng} / \mathrm{mL}(50 \mathrm{nmol} / \mathrm{L})$ \\
\hline US Endocrine Society & Sufficiency & $>20 \mathrm{ng} / \mathrm{mL}(50 \mathrm{nmol} / \mathrm{L})$ \\
& Deficiency & $<20 \mathrm{ng} / \mathrm{mL}(50 \mathrm{nmol} / \mathrm{L})$ \\
& Insufficiency & $21 \mathrm{and} 29 \mathrm{ng} / \mathrm{mL}(52.5-72.5 \mathrm{nmol} / \mathrm{L})$ \\
\hline
\end{tabular}


mechanisms of how genes function within biological networks [14]. Pathway analysis has subsequently been developed to perform statistical tests on the lists of genes involved in the biological pathways for a significant relationship with a particular phenotype or observable trait [17].

Favaro [14] in 2017 reported the results of a pathway analysis of a list of genes affected in AIS. He found that the multiple pathways were significantly affected in AIS, including those of cancer; the endocrine system; the lung and heart stress response and repair; stem cell differentiation; as well as skeletal tissue growth, development, and repair.

It is noteworthy that vitamin D was involved in some pathways, including the spinal cord injury pathway, the lung fibrosis pathway, the endochondral ossification pathway, and the endocrine resistance pathway [14].

\section{Spinal cord pathway and lung fibrosis pathway}

Spinal cord injury and lung fibrosis pathways involve glial scar formation and focal adhesion in response to spinal cord injury [18]. Vitamin D and its analogs have been established to have an association with fibrosis regulation. Vitamin D has been used to treat fibrosis in multiple organs, including the lung, bone, and liver [19-23]. Early vitamin D supplementation significantly reduced the severity of bleomycin-induced pulmonary fibrosis in mice [21]. In bones, a 3-9-month treatment course of calcifediol significantly decreased bone marrow fibrosis [19]. Similarly, sufficient vitamin D levels (> $50 \mathrm{nmol} / \mathrm{L}$ ) decreased the occurrence of rapid fibrosis progression in chronic hepatitis patients [20]. It is possible that in a subset of AIS patients, tethering of the nerve roots may occur following spinal injuries. Fibrosis of the paravertebral muscles is observed after injury [24]. Moreover, compression of the sciatic nerve in rats induced fibrosis near the lesions and the ipsilateral dorsal root ganglion. This occurred 3 weeks after the compression using the Silastic tube [25].

\section{Endochondral ossification pathway}

Genetic pathway analysis also showed that genes related to the endochondral ossification pathway were over-represented [14]. The pathway described genes involved in the replacement of the cartilaginous tissue by the bone tissue. Although the regulation of this process includes growth hormones, thyroid hormones, and transcription factors, among other molecules, vitamin $\mathrm{D}$ is also essential for the regulation of endochondral ossification [26,27].

\section{Endocrine resistance pathway}

The endocrine resistance pathway describes the underlying biological mechanisms for resistance to the treatment of hormonal-responsive breast cancer [14]. Problems in regulating and responding to hormones could be the underlying cause of AIS [14]. Women with AIS are more likely than men to develop a spinal curve that progresses in severity. This indicates that a manifestation of the problems in estrogen regulation may be an underlying cause of AIS, given that women tend to have higher estrogen levels than men $[28,29]$.

Several factors affect estrogen production, and vitamin $\mathrm{D}$ is a significant factor. Vitamin D deficiency reportedly reduces estrogen production [30]. This has been reported by Kinuta et al. [30] in 2000 who studied the role of vitamin $\mathrm{D}$ in the regulation of estrogen synthesis, using the vitamin D receptor (VDR) in null mutant mice. The authors reported that the mutant mice had gonadal insufficiencies that were normalized by estrogen supplementation and were partially normalized by calcium supplementation [30]. They concluded that vitamin D contributed to the regulation of estrogen synthesis [30] and that its deficiency reduced estrogen production. Female rats with severe vitamin D deficiency had impaired fertility [31]. However, a study demonstrated that 4-week supplementation of vitamin D3 to women aged 18-22 years reduced the estradiol levels by $3 \%$ [32]. It is possible that the healthy volunteers had low normal vitamin $\mathrm{D}$ levels $(55 \mathrm{nmol} / \mathrm{L})$ at baseline [32] and saturating the VDR receptors with additional vitamin D3 did not increase estrogen production.

\section{Central Nervous System and Vitamin D}

Abnormalities in the morphology and function of the central nervous system have long been implicated in the etiopathogenesis of AIS. Cervicothoracic syrinx [33,34], low-lying cerebellar tonsils [35-37], and morphological abnormalities in the midbrain [38], pons medulla [39], and vestibular system [40] have all been reported in subgroups of AIS subjects.

Functionally, AIS patients are reported to have a 
range of abnormalities in postural balance, proprioceptive disturbance [41,42], oculo-vestibular function [43], vestibular-evoked postural response [44], somatosensory functions [45-47], and motor control [48]. Beaulieu et al. [47] in 2009 and Haumont et al. [49] in 2011 both showed that postural balance dysfunction is related positively to the severity of curvatures. AIS patients with greater curvatures and poorer balance control use fewer anticipatory strategies to stabilize body oscillations [49].

\section{Central nervous system morphological changes and vitamin D}

The morphologic changes observed in the brain of AIS subjects may be related to vitamin D deficiency or insufficiency. Growing evidence is showing that vitamin D is involved in brain development in rats and mice [50-52] because VDRs are expressed widely in the temporal, orbital, and cingulate cortices; in the thalamus; midbrain-pontine central grey and spinal cord in rats and mice [50,53-55]. Hawes et al. [51] in 2015 determined the influence of vitamin D deficiency during pregnancy on brain development in mice. Female albino house mice that did not have vitamin D3 receptors were placed on either a vitamin D (control) or a vitamin D-deficient diet for 5 weeks prior to and during pregnancy [51]. Fetal brains were then examined morphologically, and gene expression was analyzed. Vitamin $\mathrm{D}$ deficiency during pregnancy reduced fetal crownrump length and head size [51]. Other similar studies showed that the offspring of vitamin D3-deficient rats were heavier than the control animals, although there was no difference in the ratio of brain to body weight between the groups [50]. They had larger lateral ventricles [56,57], double the size of those in controls even when corrected for the increased hemispheric volume [50]. The mice also had a thinner cortex [56]. Similarly, Caucasian elderlies deficient in 25-hydroxyvitamin $\mathrm{D}(25[\mathrm{OH}] \mathrm{D})(<50 \mathrm{nmol} /$ L) had larger ventricles than those of subjects with normal 25(OD)D levels (>50 nmol/L) [58]. Vitamin D depletion is reportedly associated with lower brain volume [59].

In addition, McGrath et al. [50] in 2004 and Eyles et al. [60] in 2005 have shown that the VDR is also expressed in the human brain. They reported the presence of $1 a$-hydroxylase, the enzyme responsible for the formation of the active vitamin $\mathrm{D}$ in the human brain [60]. The distribution of VDR in the human brain is similar to that reported in rodents [60]. VDR is found in the hippocam-

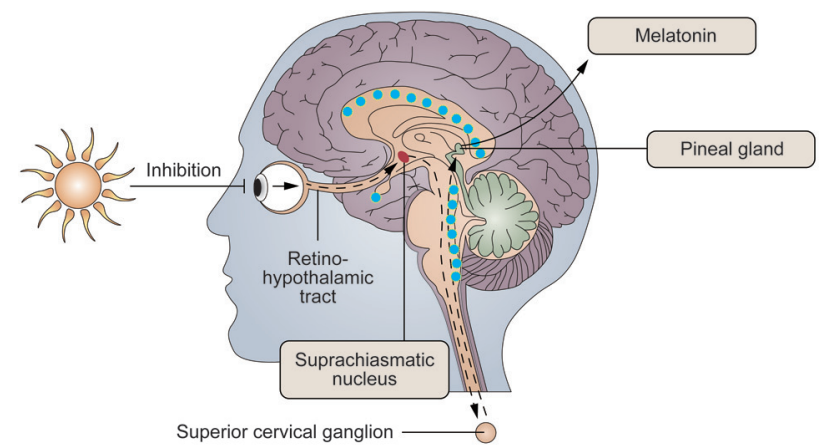

Fig. 1. The possible interaction of melatonin and vitamin D. Symbol (R) refers to the sites in which vitamin $D$ receptor are strongly expressed in the brain. It was speculated that the 25-hydroxyvitamin D3 acted as mediator, bringing the 'message of light' from the retina to the pineal glands, resulting in decreased melatonin synthesis.

pus; cortex; limbic systems; and the olfactory, visual, and auditory systems in the human brains (Fig. 1) [50,61,62]. This may suggest that vitamin D can modulate brain function in health and disease [52].

Further, Kuether and Piatt [63] in 1998 described a case of marked vitamin D deficiency. The patient presented with vitamin D-resistant rickets that involved the base of the cranium and precipitated the development of Chiari malformation and associated syringomyelia [63], features observed in some AIS patients. It is possible that vitamin D3 deficiency in some AIS patients causes similar subclinical changes. Further, Zhang et al. [64] in 2016 reported spinal cord abnormalities in $18.7 \%$ of the 'presumed' infantile and juvenile IS patients. Of these, $65 \%$ had ArnoldChiari malformation with or without syringomyelia.

\section{Postural balance, motor performance, and vitamin $D$}

Vitamin D deficiency causes poorer balance or posture control in mice and humans [7,65-67]. Kalueff et al. [68] in 2004 have shown that mice with VDR ablation had impaired motor performance. Therefore, it is possible that VDR deficiency affects the modulation of brain neurotransmitters, such as acetylcholine and catecholamines, and disrupts the vitamin D-VDR signaling pathways, resulting in impaired motor performance [68].

Minasyan et al. [65] in 2009 also examined the balance functions in VDR deficient mice. They found that the VDR deficiency in mice was associated with decreased balance functions. These findings may be relevant to poorer balance and posture control in humans with low vitamin D levels [65]. Beauchet et al. [66] in 2011 studied 
the association between the stride-to-stride variability of stride time (STV) and serum 25(OH)D levels in adults $>65$ years old. Results showed that subjects with serum $25(\mathrm{OH}) \mathrm{D}<10 \mathrm{ng} / \mathrm{mL}$ representing severe vitamin D deficiency had a low lower limb proprioception score and a high STV (worse performance) [66]. A similar study by Krause et al. [67] in 2014 evaluated the impact of vitamin D level on postural body sway (PBS) in 342 elderly subjects. They evaluated the different PBS parameters on a force plate with feet in close stance or hip-width stance with eyes open or closed [67]. Patients with significant vitamin D deficiency $(<10 \mu \mathrm{g} / \mathrm{mL})$ had significantly higher PBS and hip-width stance than those with normal serum vitamin D levels (>30 $\mu \mathrm{g} / \mathrm{L})$ [67]. In another study, patients who were $>60$ years old and whose serum $25(\mathrm{OH})$ $\mathrm{D}$ levels were $<50 \mathrm{nmol} / \mathrm{L}$ had a lower stability index than those with normal serum 25(OH)D [7]. Patients with serum $25(\mathrm{OH}) \mathrm{D}$ level $>50 \mathrm{nmol} / \mathrm{L}$ had significantly better standing balance, gait, and chair stand performance compared to those with serum 25(OH)D $<50 \mathrm{nmol} / \mathrm{L}$ [7].

Patients with vitamin D3 deficiency who were supplemented with vitamin D3 showed improved postural balance [69-71]. Anek et al. [69] in 2015 examined the effect of short-term supplementation of vitamin D3 on the balance ability of 52 women aged $45-55$ years old. They found that the balance ability of 26 women supplemented with 20,000 IU/wk vitamin D2 for 4 consecutive weeks was significantly improved compared with that at baseline and compared with that of the control group who had not received any supplementation. Similar findings were reported by Cangussu et al. [70] in 2016 in younger (50-65 years) postmenopausal subjects with vitamin D deficiency. They supplemented one group with 1,000 IU/day vitamin D3 orally; the other group received no supplementation. After 9 months, the 25(OH)D level of the supplemented group increased; no such increase was observed in the control group [70]. The balance of the supplemented group improved, and they exhibited a reduction in body sway, as measured with stabilometry. In contrast, there was no improvement in the balance of the control group [70].

Thus, it is clear that vitamin D may play a role in the cerebral process of postural balance [7]. However, the underlying mechanism remains unknown. Sanyelbhaa and Sanyelbhaa [72] in 2015 reported a high prevalence of abnormal ocular vestibular-evoked myogenic potentials and cervical vestibular-evoked myogenic potentials in patients with vitamin D deficiency, suggesting possible otolith dys- function that affected both the utricle and saccule. Thus, it is possible that vitamin D deficiency may affect postural balance through disturbance of the vestibular system, which has been found to be dysfunctional in AIS patients [44].

\section{Skeletal Growth, Menarche, and Vitamin D Status}

Several studies have reported that the skeletal growth pattern in AIS subjects is disturbed [73-77]. This has been attributed to the age of onset of menarche [76,77], reduced serum vitamin $\mathrm{D}$ level, and/or polymorphism or variations in the VDRs [78].

AIS subjects are reportedly taller than healthy controls [73-77]. However, after the age of 13 years, the height difference between AIS and control subjects disappeared $[77,79]$. With respect to the sexual maturity, Siu King Cheung et al. [80] in 2003 reported that girls with AIS were shorter before menarche; however, they grew taller and had a longer arm span during the growth spurt compared to healthy controls. Studies have shown that there are insignificant differences in the height between patients and controls at the end of the growth period, and the growth pattern of AIS patients has thus far been regarded as essentially normal $[76,77]$. In fact, in a recent review, Schlösser et al. in 2014 stated that there was only weak evidence in support of corrected body height changes as an etiological factor of AIS [6].

These different findings may be related to the age of onset of menarche reported in different studies $[76,77,80]$. Ylikoski [76] in 2003 and Goldberg et al. [77] in 1993 reported that AIS girls experience earlier menarche with an earlier growth spurt. Other authors have reported contradictory findings [81-84]. Warren et al. [81] in 1986 reported a higher prevalence of scoliosis in ballet dancers, all of whom had delayed menarche. Mao et al. [82] in 2011 found that the average age of onset for menarche in Chinese girls with AIS girls was significantly later than in normal controls. Yim et al. [83] in 2012 also reported that Chinese AIS girls had an average delay of 0.49 years in the age of onset of menarche compared to healthy controls.

Many factors influence the age of onset of menarche. These include genetics, estrogen level, vitamin D status, polymorphism of VDR, and latitude [78,85] (Table 4). Twin studies have shown that as much as $68 \%$ of the variance in age at menarche may be genetically determined 
Table 4. The non-genetic determinants of age of onset of menarche

\begin{tabular}{lll} 
Variable & \multicolumn{1}{c}{ Early menarche } & Late menarche \\
\hline Ethnicity & Black girls & Whites as compared to Black girls \\
\hline Latitude & Lower latitude & Higher latitude, north of 300 \\
\hline Arthropometric parameters & Higher subcutaneous fat and BMI & Low BMl \\
Nutrition & Increased energy-adjusted intake & Intake of yogurt \\
& High animal protein & Vegetable proteins \\
& Caffeinated and artificially sweetened soft drink & Reduced fat intake \\
& Sugar sweetened beverages & \\
& Soy based products & Low socioeconomic status \\
Environmental factors & High socioeconomic status & Low parental education \\
& High parental education & Rural environment \\
& Absence of biological father & \\
\hline
\end{tabular}

$\mathrm{BMI}$, body mass index.

[85]. A decrease in the estrogen level is related to a delay in menarche [82]. Likewise, vitamin D deficiency and VDR polymorphism affect the timing of menarche $[78,86]$. Villamor et al. [86] in 2011 showed that vitamin D3 deficiency is associated with an early onset of menarche by as much as 9 months. Latitude reportedly affects the time of onset of menarche, possibly through its influence on melatonin secretion and vitamin D synthesis [87-89]. Girls who live at higher latitudes appear to experience menarche later than girls who live closer to the equator [87-89]. Grivas et al. [87] in 2006 attributed the differences in the age of onset of menarche in different latitudes to the possible differences in melatonin secretion [87]. However, it is also possible that the differences in menarche onset are related to the serum vitamin D level. At higher latitudes where the ultraviolet radiation is less intense, the cutaneous synthesis of vitamin $\mathrm{D}$ is decreased $[88,90]$. This may also be related to the delay in menarche onset. Dossus et al. [88] in 2013 showed that on a continuous scale, an increase of $1^{\circ}$ latitude was associated with 0.04 years older age of onset of menarche, whiles a $1-\mathrm{kJ} / \mathrm{m}^{2}$ increase in the annual ultraviolet radiation dose resulted in a 0.42 years younger age at menarche. Hagenau et al. [90] in 2009 showed that there was a $25(\mathrm{OH}) \mathrm{D}$ level decrease with latitude in European Caucasians; however, this was not observed in non-Caucasians. Studies have shown that an increase in the serum vitamin D level is associated with earlier menarche onset and vice versa $[88,90]$.

Overall, the results are controversial. Studies have shown that both low and increased serum vitamin D level are associated with an earlier age of onset of menarche $[86,88]$. The contradictory findings may be attributable to the confounding effects of childhood obesity and higher leptin levels [91]. In obese girls, more serum 25(OD) $\mathrm{D}$ is bound to the adipose tissues. Moreover, the higher amount of adipose tissues increases the tissue dilution of the vitamin, resulting in lower serum 25(OH)D levels, influencing the outcome.

Furthermore, the mechanism underlying the association of vitamin $\mathrm{D}$ with the timing of menarche has not been clearly elucidated. It is possible that vitamin $\mathrm{D}$ acts through estrogen to affect the timing of menarche. The deficiency of vitamin D may reduce estrogen synthesis [30] and the expression and activity of several enzymes related to the production of sex steroids [92]. In addition, the interactions between the signaling pathways of estrogen and 1,25-vitamin D3 have also been identified [93].

\section{Osteopenia and Vitamin D}

Osteopenia is a condition characterized a lower than normal BMD. In particular, it is defined as BMD with a T-score between -1.0 and -2.5 . T-score is the number of standard deviations above or below the mean value for a healthy 30 -year-old adult of the same sex and ethnicity as the patient. Recent studies have shown that $29.5 \%$ [94] to $38 \%$ of AIS patients have osteopenia $[3,95,96]$. Burner et al. [97] in 1982 were the first to report relative osteoporosis in children with IS. Similarly, Velis et al. [98] in 1988 used the Singh femoral trabecular index, a classification 
system for the bone density of the femoral neck based on the visibility of the trabecular types that can be seen in the femoral neck to show that scoliosis patients presented with early trabecular bone loss in the hips. Thereafter, osteopenia in AIS patients has been confirmed in many studies [95,99-101] using dual photon-absorptiometry and dual energy X-ray absorptiometry. Osteopenia has been found not only in the spine $[3,99]$, but also in the radius [102], hips [99-101], and tibia; therefore, the decrease in bone density is a generalized rather than a local phenomenon.

Follow-up studies have also shown that the bone quality in AIS patients is also affected [100,102]. Tam et al. [102] in 2014 found that the cortical density of the radius of the non-dominant hand of AIS patients was significantly reduced as compared to that in healthy controls. The trabecular density, trabecular number, and thickness also reportedly decreased [102], making the patients prone to fracture.

Further, the presence of a generalized reduction in BMD prompted Cheng et al. [3] in 1999 to suggest that osteopenia may have an etiopathogenetic role in AIS. Lee et al. [4] in 2005 demonstrated that BMD was inversely related to curve severity in 919 girls with AIS during the peri-pubertal period. AIS patients with lower BMD generally had a higher Cobb angle, while those with normal BMD had smaller curves [4]. This concurred with the findings of Wang et al. [101] in 2017 In fact, Hung et al. [5] in 2005 who followed up a cohort of 324 girls with AIS until skeletal maturity or progression of curves $\geq 6^{\circ}$ found that osteopenia was a significant prognostic factor for curve progression.

Lee et al. [4] in 2005 compared the calcium intake and time spent in physical activities in 596 girls with AIS girls and 302 age-matched healthy controls. They found that the median calcium intake of AIS patients did not differ significantly from that of healthy controls. However, the median time spent by the former (AIS patients) in physical activities was slightly less than that spent by the controls [5]. Other studies have shown that osteopenia observed in AIS patients is related to vitamin D insufficiency and deficiency $[10,103,104]$. Longitudinal and cross-sectional studies have also demonstrated that the 25(OH)D level positively correlated with BMD in healthy children and adolescents [105-108]. The serum 25(OH) D level of pre-pubertal children at ages 7.6, 9.9, and 11.8 positively correlated with cortical bone mineral content
(BMC), cortical thickness, and predicted bone strength at the age of 15.5 years [108]. Pubertal girls with lower vitamin D levels were at risk of not reaching the maximum peak bone mass, particularly at the lumbar spine [105]. Moreover, Balioglu et al. [10] recently demonstrated a negative correlation between serum vitamin $\mathrm{D}$ levels and the Cobb angle. Thus, these results further suggest that vitamin D may play an etiopathologic role in AIS development.

The age of onset of menarche is a determinant factor of peak BMD in young girls. Fox et al. [109] in 1993 and Tuppurainen et al. [110] in 1995 reported that BMD is related to the age of onset of menarche. Early menarche is associated with higher circulating estrogen levels during and after menarche $[111,112]$ and a high peak bone mass [113]. Late menarche is associated with a low BMD $[109,110,113]$. A Chinese cohort study found patients aged $<40$ years who had experienced late menarche (at age $>14$ years) had an approximately two-fold higher risk of low areal BMD at the hips [114]. Similarly, a Korea National Health and Nutrition Examination Survey (20082011) showed late menarche is associated with a lower BMD in the lumbar spine [114]. The age at menarche is correlated not only with BMD, but also with bone microstructure [115]. Young healthy girls with a higher age of onset of menarche displayed lower total volumetric BMD, cortical volumetric BMD, and cortical thickness at the forearm than those with a lower age of onset of menarche [115].

\section{Hormones and Vitamin D}

Many hormones and metabolites have been implicated in the etiopathogenesis of IS. Among these, estrogen, melatonin, and leptin are important [116-121]. Platelet calmodulin and osteopontin were possibly of secondary importance in AIS pathogenesis. It is possible that all these hormones and proteins interact to influence BMD and vertebral bone quality, thereby affecting AIS development.

\section{Estrogen and vitamin $D$}

AIS prevalence is higher in girls than in boys, particularly when the Cobb angle is $>30^{\circ}$ [122]. Further, the association of greater curvatures with delayed menarche has raised the interest regarding estrogens in the scoliosis 
communities because estrogens may play a role in the etiopathogenesis of IS [29]. The estrogen level in AIS subjects has been extensively studied. Raczkowski [123] in 2007 found no difference in the estradiol level of 27 girls with AIS and age-matched controls. The findings were supported by Sanders et al. [124] in 2007. In contrast, Kulis et al. [116] in 2006 found that the estradiol level of girls with AIS was lower than that of the age-matched controls. This was in agreement with the report of Esposito et al. [117] in 2009. In addition, Kulis et al. [125] in 2015 found that the reduction in estradiol level occurred both preand post-menarche onset in AIS patients as compared to that in healthy controls. The reduction was more significant before than after menarche onset [125].

Estrogen has multiple functions. In addition to its reproductive functions, it regulates skeletal growth and development, promotes bone absorption, is involved in matrix metabolism, and maintains normal bone density [29]. It is also involved in the normal closure of the growth plates in both sexes [126]. Thus, reduced estrogen production delays the development of bone maturity [126]. In fact, hypoestrogenism is associated with a higher prevalence of AIS [81].

Estrogen does not act alone, it interacts with melatonin and vitamin $\mathrm{D}$. This interaction is achieved by the modulation of the activity of melatonin; $17-\beta$-estradiol, an estrogen, affects the functions of melatonin [127] and

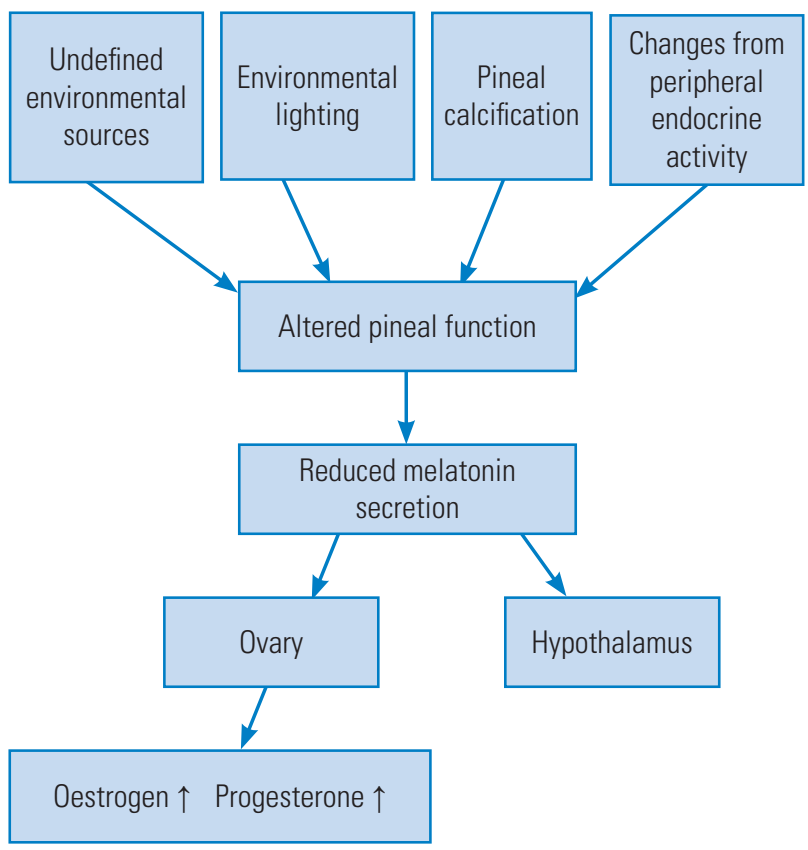

Fig. 2. The influence of melatonin on oestrogen production. inhibits its melatonin [128]. The signaling pathways of estrogen and melatonin interact (Fig. 2) [127,129]. In addition, estrogen interacts with vitamin D (Fig. 3). Further, estrogen stimulates renal $1 \alpha$-hydroxylase activity, converting $25(\mathrm{OH}) \mathrm{D}$ to 1,25 -dihydroxyvitamin $\mathrm{D}$, a biologically more active form of vitamin D [130]. 17- $\beta$-estradiol also upregulates the expression of the VDR gene [131] and increases intestinal calcium absorption through vitamin Ddependent mechanisms. Vitamin $\mathrm{D}$ is also involved in the regulation of estrogen synthesis [30]. Moreover, $1,25(\mathrm{OH})_{2}$ vitamin D3 upregulates the estrogen-binding proteins [132]. Further, the estrogen and VDR genotypes interact and influence the age of menarche [133] and BMD [134].

\section{Melatonin and vitamin $\mathrm{D}$}

Melatonin, also known as $\mathrm{N}$-acetyl-5-methoxy tryptamine, is a hormone produced by the pineal gland in animals; it regulates sleep and wakefulness. Melatonin deficiency has been implicated in AIS pathogenesis $[135,136]$. However, subsequent studies did not agree with the theory that melatonin deficiency is a primary cause of AIS [137-139]. More recent trials, however, show that patients with severe AIS have dysfunctional melatonin signaling

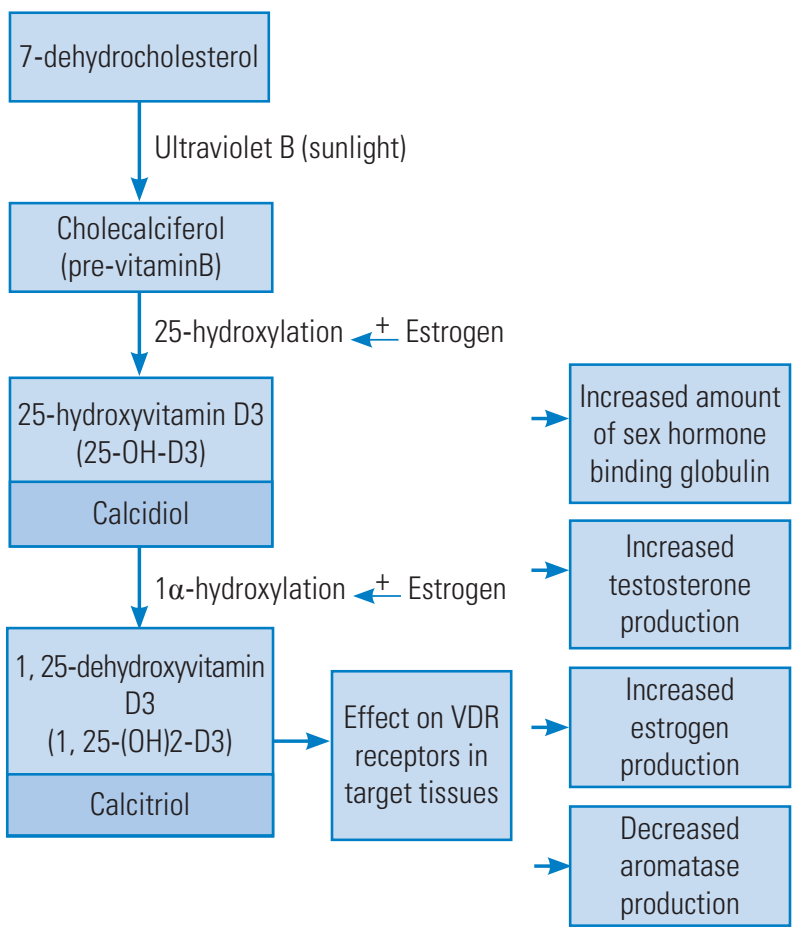

Fig. 3. The interaction among oestrogen, vitamin D and VDR. VDR, vitamin $\mathrm{D}$ receptor. 
$[118,119,140]$.

In AIS patients, melatonin possibly exerts its effects through its influence on bone growth and development. Melatonin induces the proliferation and stimulation of type I collagen synthesis in primary human osteoblasts $[141,142]$ and enhances osteoid mineralization and osteoblast differentiation in mice and rat cell cultures [143]. Reduce melatonin secretion may contribute to the development of osteoporosis in humans [129]. Epidemiological studies on a study sample comprising more than 38,000 postmenopausal women who worked night shifts for $\geq 20$ years demonstrated significantly increased risks of wrist and hip fractures over an 8-year follow-up period in these women as compared to those in women who had never worked night shifts [144]. Night shift work disturbs the patterns of melatonin secretion with severe circadian rhythm disruption [145].

It is noteworthy that vitamin D and melatonin reportedly interact with each other. In multiple sclerosis patients treated with interferon $\beta$ (IFN- $\beta$ ), natural cell-signaling proteins produced by the body that have antiviral, immunomodulatory, and antiproliferative properties, melatonin secretion was negatively correlated with alterations in the serum 25(OH)D levels [146]. In a randomized control study, 3-month supplementation with a high dose of vitamin D to 40 IFN- $\beta$ treated multiple sclerosis patients significantly decreased the overnight secretion of melatonin [146]. The reduction in the serum 25(OH)D levels was accompanied by an increase in the nighttime secretion of melatonin [146].

It is possible that 25-hydroxyvitamin $\mathrm{D}$ is a mediator in melatonin production [146]. Melanin production from the pineal gland is stimulated by darkness and inhibited by light. Photic stimulation from the retina is transmitted to the pineal gland via the suprachiasmatic nucleus of the hypothalamus [147]. VDR is strongly expressed in the supraoptic nucleus of the hypothalamus; therefore, Golan et al (2013) speculated that $25(\mathrm{OH}) \mathrm{D}$ acted as mediator, transmitting the 'message of light' to the pineal glands, leading to decreased melatonin synthesis (Fig. 1) [146].

\section{Leptin and vitamin $D$}

Leptin is an adipocyte-derived hormone; once synthesized, it is released into the blood stream to stimulate the brain for the regulation of appetite and energy consumption. In obese subjects with a large fat mass, leptin secre- tion is increased. In contrast, it is reduced in lean individuals.

Leptin primarily suppresses appetite and maintains the energy homeostasis. It also affects bone metabolism [148] and the production of gonadal hormones by its effects on the hypothalamus [149]. Several girls with AIS girls have low leptin levels with other risk factors associated with AIS, including a low body mass index (BMI), reduced bone mass, and delayed puberty $[80,150,151]$; thus, low leptin levels are believe to be a cause of AIS [120,121].

Leptin primarily influences bone metabolism via two different pathways, the central and peripheral pathways that favor the breakdown and formation of the bones, respectively. In mice, the intracerebroventricular infusion of leptin stimulates hypothalamic leptin receptor expression and the sympathetic nervous system, enhancing bone resorption $[151,152]$. However, peripherally, leptin promotes the differentiation of bone marrow stromal cells into osteoblasts and decreases the breakdown of bones, thus encouraging bone formation [153,154]. Thus, skeletal bone mass depends on the interplay of these two mechanisms [153]. Low leptin levels are reportedly associated with abnormal bone microarchitecture [149].

Leptin may also possibly influence AIS pathogenesis via its effects on puberty, although the results are controversial. Leptin plays a significant role in the maintenance of the hypothalamic-gonadal-pituitary axis; it acts on the hypothalamus, pituitary gland, and gonadal glands as if they form a single entity acting collaboratively. Matkovic et al. [155] in 1997 demonstrated that leptin levels were inversely correlated with age of onset of menarche in girls with and without AIS. Low leptin levels are associated with delayed puberty $[149,150]$. The replacement of leptin in deficient individuals restored puberty and fertility [156].

Burwell et al. [121] in 2016 recently postulated that a reduction in the serum leptin levels plays a role in the cascade of AIS pathogenesis. Clinical studies have shown that serum leptin concentration is proportional to the total body weight, fat mass, [148] and vitamin D level [157]. Elevated serum leptin levels are observed in obese individuals, while reduced levels are seen in those with a low body weight [148]. Clark et al. [120] in 2014 investigated the relationship of BMI at the age of 10 years and the presence of scoliosis at the age of 15 years. They found a negative association between the BMI/body weight at the age of 10 years and scoliosis at the age of 15 years, with a $20 \%$ reduced risk of scoliosis per one standard deviation 
increase in the BMI. This suggested that girls with a lower BMI are at a higher risk of scoliosis [120].

Leptin levels are also associated with serum vitamin D levels. Menendez et al. [158] in 2001 and Kim et al. [159] in 2013 have shown an inverse relationship between leptin levels and $25(\mathrm{OH}) \mathrm{D}$ levels. A reduction in the $25(\mathrm{OH}) \mathrm{D}$ level is associated with an increase in the leptin level and vice versa. In obese subjects, leptin is secreted by the adipose tissue to induce satiety. In the presence of abundant adipose tissue, more vitamin $\mathrm{D}$ is absorbed into the tissue, reducing the circulating vitamin $\mathrm{D}$ level. In contrast, in lean individuals who have less adipose tissue, less leptin is secreted. Moreover, less vitamin D is absorbed into the adipose tissue. This increases the circulating vitamin $\mathrm{D}$ levels [158]. Thus, it is clear that 25(OH)D negatively and powerfully controls leptin secretion by the human adipose tissue [158].

\section{The Role of Vitamin D in the Etiopathogenesis of Adolescent Idiopathic Scoliosis}

Currently, AIS is considered a multifactorial heterogeneous disease [160], with genetic and environmental factors influencing its etiopathogenesis $[161,162]$. Vitamin D deficiency and osteopenia were prevalent among AIS patients [10] and were positively correlated with the Cobb angle. Therefore, we speculated that vitamin $\mathrm{D}$ deficiency may play a role in AIS development, possibly by influencing fibrosis regulation [163], postural control, and regulation of bone metabolism [10] (Table 5).

In children with vitamin $\mathrm{D}$ deficiency, spinal cord or spinal column injury in children may be repaired by fibrosis, setting the background for the tethering of the nerve roots. Abe et al. [24] in 2017 injured the right side of the paravertebral muscles of 30,8 -week-old male rats. Thereafter, they performed histological examination and comparison of the muscle fibers and dorsal root ganglia

Table 5. Factors that contribute to decreased serum vitamin $D$ level

\begin{tabular}{l} 
Decrease in fat intake \\
Decrease in cholesterol intake \\
Decrease in sun exposure \\
Staying in-door \\
Higher latitude \\
Insufficient magnesium intake \\
Gut absorption problems \\
\hline
\end{tabular}

on both the sides 1-3 weeks post-intervention. They found the cicatrix formed after the injury may sensitize the dominant nerve in the dorsal root ganglia [24]. Li et al. [25] in 2016 studied the effects of compression of the sciatic nerve in rats to investigate the pathological alterations in the neurons of the dorsal root ganglia [25]. They reported at 3 weeks after the compression, collagen fibers accumulated around the compressed sciatic nerve, and at 8 weeks, excessive collagen formation with muscle atrophy was observed [25]. The volume of collagen gradually and significantly increased following sciatic nerve compression. The amount of collagen I fibers surrounding the ipsilateral dorsal root ganglion was higher than that on the contralateral side [25], suggesting that injuries to the paravertebral muscles and nerve roots are healed with fibrosis. It is possible that in a subset of AIS patients with vitamin D deficiency, spinal injury in childhood is healed by fibrosis, with resultant nerve root tethering. As per clinical reports, fibrosis and scar tissue formation after surgery in childhood may be associated with AIS [164,165]. Lebel and Lebel [164] in 2016 reported a case of a female patient with AIS who underwent surgical excision of a $4-\mathrm{cm}$ benign ganglioblastoma from the left posterior rib cage at the age of 3 years. Post-surgical radiographs at the age of 8 years showed fusion of left 4 th and 5 th ribs. The patient was diagnosed with AIS at 11 years of age [164]. Similarly, Brooks et al. [165] in 2009 reported a case of AIS, possibly secondary to right inguinal herniorrhaphy performed before 6.25 years of age. By the age of 6.5 years, an asymmetric posture was apparent in a casual photograph, and after puberty, a marked deformity was evident [165].

Artaza and Norris [163] in 2009 exposed mesenchymal multipotent cells to the active form of vitamin D. They found that vitamin $\mathrm{D}$ decreased the expression of transforming growth factor $\beta 1$ and the plasminogen activator inhibitor, both of which are profibrotic factors, leading to reduced collagen deposition.

Vitamin D deficiency is also found to reduce postural control; supplementation of vitamin D improves the postural control in elderly individuals with vitamin D deficiency [69-71]. Whether this has any implications in AIS subjects warrants further investigation.

Insufficiency and deficiency of vitamin D may also play a role in AIS pathogenesis through its effects on bone metabolism. Vitamin D possibly interacts with estrogen, melatonin, and leptin to affect the BMD and BMC of the bones, including the vertebrae $[3,9,10,30,131,146,158]$. 
Recently, vitamin K2 was also found to be important for regulating bone metabolism. Vitamin K2 facilitates the deposition of calcium in the bones by the carboxylation of osteocalcin, the synthesis of which is induced by $1,25-(\mathrm{OH}) 2 \mathrm{D} 3$ [166]. Vitamin D deficiency reduces the carboxylation of osteocalcin and reduces the BMC of the total body and the lumbar spine [167]. It is noteworthy that many peri-pubertal healthy adolescents have subclinical deficiency of vitamin D [105,168-170] and vitamin K2 $[167,171,172]$. This may be attributable to the high bone turnover in children $[105,172]$ and the fat-restricted diet that is commonly enforced by the parents, given the fact that both vitamin D and K2 are fat-soluble vitamins. Deficiency of vitamin $\mathrm{D}$, vitamin K2, estrogen, melatonin, and leptin levels is associated with a reduction in the BMD $[8,9,129,150,173]$. It is possible that the resultant osteopenia from the deficiencies make the vertebrae susceptible to wedge deformity in the early stages of AIS [174-181], contributing to the initiation and/or progression of the curvature.

Recent studies have shown that asymmetric loading of the osteopenic vertebrae may cause vertebral wedging through creeping, a continuous deformation under constant load [182,183]. Lowered vertebral BMD is associated with a higher Cobb angle and increased risk for curve progression $[4,5,184]$. Studies have shown that sustained compressive loading can cause progressive and measurable creep deformity in osteopenic elderly human vertebrae [182,183], with a mean $\mathrm{BMD}<0.15 \mathrm{~g} / \mathrm{cm}^{3}$ that results in vertebral wedging [182]. Wren et al. [185] in 2017 reported that lateral thoracic vertebral body wedging is negatively correlated with the vertebral cross-sectional area (CSA) in girls with AIS. Thus, vertebral body wedging is more likely to occur in the thoracic spine that has a small vertebral CSA, particularly in the presence of osteopenia [186]. In skeletally immature patients, continuous asymmetric growth on the concave and convex sides of a scoliosis curve would increase vertebral wedging, further contributing to an increase in the curvature $[185,187]$.

\section{Conclusions}

Our literature review demonstrated an association between vitamin D status and BMD, menarche, and other hormones. Although lower vitamin D levels are correlated with the Cobb angle, the relationship between vitamin $\mathrm{D}$ and AIS may not be casual. Further studies are required to determine whether vitamin D definitely plays a casual role in the etiopathogenesis of AIS and whether vitamin $\mathrm{D}$ deficiency is related to the tethering of the nerve roots and postural control dysfunctions observed in some AIS subjects. Longitudinal studies may also be required to examine the effects of fat-restricted diets as well as vitamin $\mathrm{D}$ and $\mathrm{K} 2$ supplementation on the progression and management of the scoliosis curves.

Further, it may be interesting to determine if the widespread deficiencies of vitamin D and K2 in adolescents are related to the increased need for vitamin D and K2 during pubertal growth and/or to the adherence to the now challenged fat- and cholesterol-restricted diets [188] that have been promoted since the early 1980s to reduce the risk of cardiovascular diseases.

\section{Conflict of Interest}

No potential conflict of interest relevant to this article was reported.

\section{References}

1. Konieczny MR, Senyurt H, Krauspe R. Epidemiology of adolescent idiopathic scoliosis. J Child Orthop 2013;7:3-9.

2. Burwell RG, Dangerfield PH, Freeman BJ. Concepts on the pathogenesis of adolescent idiopathic scoliosis: bone growth and mass, vertebral column, spinal cord, brain, skull, extra-spinal left-right skeletal length asymmetries, disproportions and molecular pathogenesis. Stud Health Technol Inform 2008;135:3-52.

3. Cheng JC, Guo X, Sher AH. Persistent osteopenia in adolescent idiopathic scoliosis: a longitudinal follow up study. Spine (Phila Pa 1976) 1999;24:1218-22.

4. Lee WT, Cheung CS, Tse YK, et al. Association of osteopenia with curve severity in adolescent idiopathic scoliosis: a study of 919 girls. Osteoporos Int 2005; 16:1924-32.

5. Hung VW, Qin L, Cheung CS, et al. Osteopenia: a new prognostic factor of curve progression in adolescent idiopathic scoliosis. J Bone Joint Surg Am 2005;87:2709-16.

6. Schlosser TP, van der Heijden GJ, Versteeg AL, Castelein RM. How 'idiopathic' is adolescent idiopathic scoliosis?: a systematic review on associated 
abnormalities. PLoS One 2014;9:e97461.

7. Akdeniz S, Hepguler S, Ozturk C, Atamaz FC. The relation between vitamin $\mathrm{D}$ and postural balance according to clinical tests and tetrax posturography. J Phys Ther Sci 2016;28:1272-7.

8. Viapiana O, Gatti D, Rossini M, Idolazzi L, Fracassi E, Adami S. Vitamin D and fractures: a systematic review. Reumatismo 2007;59:15-9.

9. Gatti D, El Ghoch M, Viapiana O, et al. Strong relationship between vitamin $\mathrm{D}$ status and bone mineral density in anorexia nervosa. Bone 2015;78:212-5.

10. Balioglu MB, Aydin C, Kargin D, et al. Vitamin-D measurement in patients with adolescent idiopathic scoliosis. J Pediatr Orthop B 2017;26:48-52.

11. Wynne-Davies R. Familial (idiopathic) scoliosis: a family survey. J Bone Joint Surg Br 1968;50:24-30.

12. Riseborough EJ, Wynne-Davies R. A genetic survey of idiopathic scoliosis in Boston, Massachusetts. J Bone Joint Surg Am 1973;55:974-82.

13. Tang NL, Yeung HY, Hung VW, et al. Genetic epidemiology and heritability of AIS: a study of $415 \mathrm{Chi}-$ nese female patients. J Orthop Res 2012;30:1464-9.

14. Favaro D. Genetic pathway analysis of adolescent idiopathic scoliosis [bachelor's thesis]. Meadville (PA): Allegheny College; 2017.

15. Wang K, Li M, Hakonarson H. Analysing biological pathways in genome-wide association studies. Nat Rev Genet 2010;11:843-54.

16. Manolio TA. Bringing genome-wide association findings into clinical use. Nat Rev Genet 2013;14:549-58.

17. Moore TJ, Furberg CD. The safety risks of innovation: the FDA's Expedited Drug Development Pathway. JAMA 2012;308:869-70.

18. Kutmon M, Rieswijk L. Spinal cord injury (bos taurus) [Internet]. San Francisco (CA): WikiPathways; 2016 [cited 2017 Sep 30]. Available from: http://www. wikipathways.org/index.php/Pathway:WP3186.

19. Teitelbaum SL, Bone JM, Stein PM, et al. Calcifediol in chronic renal insufficiency: skeletal response. JAMA 1976;235:164-7.

20. Barchetta I. Could vitamin d supplementation benefit patients with chronic liver disease? Gastroenterol Hepatol (N Y) 2012;8:755-7.

21. Zhang $\mathrm{Z}$, Yu X, Fang X, et al. Preventive effects of vitamin $\mathrm{D}$ treatment on bleomycin-induced pulmonary fibrosis. Sci Rep 2015;5:17638.

22. Ramirez AM, Wongtrakool C, Welch T, Steinmeyer
A, Zugel U, Roman J. Vitamin D inhibition of profibrotic effects of transforming growth factor betal in lung fibroblasts and epithelial cells. J Steroid Biochem Mol Biol 2010;118:142-50.

23. Zhang GY, Cheng T, Luan Q, et al. Vitamin D: a novel therapeutic approach for keloid, an in vitro analysis. Br J Dermatol 2011;164:729-37.

24. Abe K, Inage K, Sakuma Y, et al. Evaluation of histological changes in back muscle injuries in rats over time. Asian Spine J 2017;11:88-92.

25. Li Q, Chen J, Chen Y, Cong X, Chen Z. Chronic sciatic nerve compression induces fibrosis in dorsal root ganglia. Mol Med Rep 2016;13:2393-400.

26. Boyan BD, Schwartz Z, Swain LD. In vitro studies on the regulation of endochondral ossification by vitamin D. Crit Rev Oral Biol Med 1992;3:15-30.

27. Dziewiatkowski DD. Vitamin D and endochondral ossification in the rat as indicated by the use of sulfur-35 and phosphorus-32. J Exp Med 1954;100:2532.

28. Moldovan F, Hassan A, Bagu E, Zaouter C, Patten SA. Could estrogen impact a new pertinent gene for AIS? Scoliosis 2015;10(Suppl 1):O2. https://doi. org/10.1186/1748-7161-10-S1-O2.

29. Leboeuf D, Letellier K, Alos N, Edery P, Moldovan F. Do estrogens impact adolescent idiopathic scoliosis? Trends Endocrinol Metab 2009;20:147-52.

30. Kinuta K, Tanaka H, Moriwake T, Aya K, Kato S, Seino Y. Vitamin D is an important factor in estrogen biosynthesis of both female and male gonads. Endocrinology 2000;141:1317-24.

31. Halloran BP, DeLuca HF. Effect of vitamin D deficiency on fertility and reproductive capacity in the female rat. J Nutr 1980;110:1573-80.

32. Knight JA, Wong J, Blackmore KM, Raboud JM, Vieth R. Vitamin D association with estradiol and progesterone in young women. Cancer Causes Control 2010;21:479-83.

33. Arai S, Ohtsuka Y, Moriya H, Kitahara H, Minami S. Scoliosis associated with syringomyelia. Spine (Phila Pa 1976) 1993;18:1591-2.

34. Isu T, Chono $Y$, Iwasaki $Y$, et al. Scoliosis associated with syringomyelia presenting in children. Childs Nerv Syst 1992;8:97-100.

35. Cheng JC, Chau WW, Guo X, Chan YL. Redefining the magnetic resonance imaging reference level for the cerebellar tonsil: a study of 170 adolescents with 
normal versus idiopathic scoliosis. Spine (Phila Pa 1976) 2003;28:815-8.

36. Chu WC, Man GC, Lam WW, et al. A detailed morphologic and functional magnetic resonance imaging study of the craniocervical junction in adolescent idiopathic scoliosis. Spine (Phila Pa 1976) 2007;32:1667-74.

37. Sun X, Qiu Y, Zhu Z, et al. Variations of the position of the cerebellar tonsil in idiopathic scoliotic adolescents with a cobb angle $>40$ degrees: a magnetic resonance imaging study. Spine (Phila Pa 1976) 2007;32:1680-6.

38. Dretakis EK. Brain-stem dysfunction and idiopathic scoliosis. Stud Health Technol Inform 2002;91:422-7.

39. Geissele AE, Kransdorf MJ, Geyer CA, Jelinek JS, Van Dam BE. Magnetic resonance imaging of the brain stem in adolescent idiopathic scoliosis. Spine (Phila Pa 1976) 1991;16:761-3.

40. Chu WC, Shi L, Wang D, et al. Variations of semicircular canals orientation and left-right asymmetry in adolescent idiopathic scoliosis (AIS) comparing with normal controls: MR morphometry study using advanced image computation techniques. Stud Health Technol Inform 2008;140;333.

41. Simoneau M, Richer N, Mercier P, Allard P, Teasdale N. Sensory deprivation and balance control in idiopathic scoliosis adolescent. Exp Brain Res 2006;170:576-82.

42. Barrack RL, Wyatt MP, Whitecloud TS 3rd, Burke SW, Roberts JM, Brinker MR. Vibratory hypersensitivity in idiopathic scoliosis. J Pediatr Orthop 1988;8:389-95.

43. Wiener-Vacher SR, Mazda K. Asymmetric otolith vestibulo-ocular responses in children with idiopathic scoliosis. J Pediatr 1998;132:1028-32.

44. Pialasse JP, Descarreaux M, Mercier P, Blouin J, Simoneau M. The vestibular-evoked postural response of adolescents with idiopathic scoliosis is altered. PLoS One 2015;10:e0143124.

45. Guo X, Chau WW, Hui-Chan CW, Cheung CS, Tsang WW, Cheng JC. Balance control in adolescents with idiopathic scoliosis and disturbed somatosensory function. Spine (Phila Pa 1976) 2006;31:E437-40.

46. Lao ML, Chow DH, Guo X, Cheng JC, Holmes AD. Impaired dynamic balance control in adolescents with idiopathic scoliosis and abnormal somatosensory evoked potentials. J Pediatr Orthop 2008;28:846-9.
47. Beaulieu M, Toulotte C, Gatto L, et al. Postural imbalance in non-treated adolescent idiopathic scoliosis at different periods of progression. Eur Spine J 2009;18:38-44.

48. Veldhuizen AG, Wever DJ, Webb PJ. The aetiology of idiopathic scoliosis: biomechanical and neuromuscular factors. Eur Spine J 2000;9:178-84.

49. Haumont T, Gauchard GC, Lascombes P, Perrin PP. Postural instability in early-stage idiopathic scoliosis in adolescent girls. Spine (Phila Pa 1976) 2011;36:E847-54.

50. McGrath JJ, Feron FP, Burne TH, Mackay-Sim A, Eyles DW. Vitamin D3-implications for brain development. J Steroid Biochem Mol Biol 2004;89-90:557-60.

51. Hawes JE, Tesic D, Whitehouse AJ, Zosky GR, Smith JT, Wyrwoll CS. Maternal vitamin D deficiency alters fetal brain development in the BALB/c mouse. Behav Brain Res 2015;286:192-200.

52. Cui X, Gooch H, Petty A, McGrath JJ, Eyles D. Vitamin $\mathrm{D}$ and the brain: genomic and non-genomic actions. Mol Cell Endocrinol 2017;453:131-43.

53. Stumpf WE, Sar M, Reid FA, Tanaka Y, DeLuca HF. Target cells for 1,25-dihydroxyvitamin D3 in intestinal tract, stomach, kidney, skin, pituitary, and parathyroid. Science 1979;206:1188-90.

54. Stumpf WE, Sar M, Narbaitz R, Reid FA, DeLuca HF, Tanaka Y. Cellular and subcellular localization of 1,25- $(\mathrm{OH}) 2$-vitamin $\mathrm{D} 3$ in rat kidney: comparison with localization of parathyroid hormone and estradiol. Proc Natl Acad Sci U S A 1980;77:1149-53.

55. Stumpf WE, O'Brien LP. 1,25 (OH)2 vitamin D3 sites of action in the brain: an autoradiographic study. Histochemistry 1987;87:393-406.

56. Eyles D, Brown J, Mackay-Sim A, McGrath J, Feron F. Vitamin D3 and brain development. Neuroscience 2003;118:641-53.

57. Feron F, Burne TH, Brown J, et al. Developmental vitamin D3 deficiency alters the adult rat brain. Brain Res Bull 2005;65:141-8.

58. Annweiler C, Montero-Odasso M, Hachinski V, Seshadri S, Bartha R, Beauchet O. Vitamin D concentration and lateral cerebral ventricle volume in older adults. Mol Nutr Food Res 2013;57:267-76.

59. Annweiler C, Beauchet O, Bartha R, Hachinski V, Montero-Odasso M; WALK Team (Working group Angers-London for Knowledge). Vitamin D and caudal primary motor cortex: a magnetic resonance 
spectroscopy study. PLoS One 2014;9:e87314.

60. Eyles DW, Smith S, Kinobe R, Hewison M, McGrath JJ. Distribution of the vitamin $\mathrm{D}$ receptor and 1 alpha-hydroxylase in human brain. J Chem Neuroanat 2005;29:21-30.

61. Gezen-Ak D, Dursun E, Yilmazer S. Vitamin D inquiry in hippocampal neurons: consequences of vitamin D-VDR pathway disruption on calcium channel and the vitamin $\mathrm{D}$ requirement. Neurol Sci 2013;34:1453-8.

62. Pérez-Fernandez R, Alonso M, Segura C, et al. Vitamin $D$ receptor gene expression in human pituitary gland. Life Sci 1997;60:35-42.

63. Kuether TA, Piatt JH. Chiari malformation associated with vitamin D-resistant rickets: case report. Neurosurgery 1998;42:1168-71.

64. Zhang W, Sha S, Xu L, Liu Z, Qiu Y, Zhu Z. The prevalence of intraspinal anomalies in infantile and juvenile patients with "presumed idiopathic" scoliosis: a MRI-based analysis of 504 patients. BMC Musculoskelet Disord 2016;17:189.

65. Minasyan A, Keisala T, Zou J, et al. Vestibular dysfunction in vitamin $\mathrm{D}$ receptor mutant mice. J Steroid Biochem Mol Biol 2009;114:161-6.

66. Beauchet O, Annweiler C, Verghese J, Fantino B, Herrmann FR, Allali G. Biology of gait control: vitamin D involvement. Neurology 2011;76:1617-22.

67. Krause M, Anschutz W, Vettorazzi E, Breer S, Amling M, Barvencik F. Vitamin D deficiency intensifies deterioration of risk factors, such as male sex and absence of vision, leading to increased postural body sway. Gait Posture 2014;39:166-71.

68. Kalueff AV, Lou YR, Laaksi I, Tuohimaa P. Impaired motor performance in mice lacking neurosteroid vitamin D receptors. Brain Res Bull 2004;64:25-9.

69. Anek A, Bunyaratavej N, Jittivilai T. Effects of shortterm vitamin $\mathrm{D}$ supplementation on musculoskeletal and body balance for prevention of falling in postmenopausal women. J Med Assoc Thai 2015;98 Suppl 8:S26-31.

70. Cangussu LM, Nahas-Neto J, Orsatti CL, et al. Effect of isolated vitamin D supplementation on the rate of falls and postural balance in postmenopausal women fallers: a randomized, double-blind, placebocontrolled trial. Menopause 2016;23:267-74.

71. Saito K, Miyakoshi N, Matsunaga T, Hongo M, Kasukawa Y, Shimada Y. Eldecalcitol improves muscle strength and dynamic balance in postmenopausal women with osteoporosis: an open-label randomized controlled study. J Bone Miner Metab 2016;34:54754.

72. Sanyelbhaa H, Sanyelbhaa A. Vestibular-evoked myogenic potentials and subjective visual vertical testing in patients with vitamin $\mathrm{D}$ deficiency/insufficiency. Eur Arch Otorhinolaryngol 2015;272:3233-9.

73. Nordwall A, Willner S. A study of skeletal age and height in girls with idiopathic scoliosis. Clin Orthop Relat Res 1975;(110):6-10.

74. Archer IA, Dickson RA. Stature and idiopathic scoliosis: a prospective study. J Bone Joint Surg Br 1985;67:185-8.

75. Nicolopoulos KS, Burwell RG, Webb JK. Stature and its components in adolescent idiopathic scoliosis: cephalo-caudal disproportion in the trunk of girls. J Bone Joint Surg Br 1985;67:594-601.

76. Ylikoski M. Height of girls with adolescent idiopathic scoliosis. Eur Spine J 2003;12:288-91.

77. Goldberg CJ, Dowling FE, Fogarty EE. Adolescent idiopathic scoliosis: early menarche, normal growth. Spine (Phila Pa 1976) 1993;18:529-35.

78. Kitagawa I, Kitagawa Y, Kawase Y, Nagaya T, Tokudome S. Advanced onset of menarche and higher bone mineral density depending on vitamin $\mathrm{D}$ receptor gene polymorphism. Eur J Endocrinol 1998;139:522-7.

79. Ylikoski M, Peltonen J, Poussa M. Biological factors and predictability of bracing in adolescent idiopathic scoliosis. J Pediatr Orthop 1989;9:680-3.

80. Siu King Cheung C, Tak Keung Lee W, Kit Tse Y, et al. Abnormal peri-pubertal anthropometric measurements and growth pattern in adolescent idiopathic scoliosis: a study of 598 patients. Spine (Phila Pa 1976) 2003;28:2152-7.

81. Warren MP, Brooks-Gunn J, Hamilton LH, Warren LF, Hamilton WG. Scoliosis and fractures in young ballet dancers: relation to delayed menarche and secondary amenorrhea. N Engl J Med 1986;314:134853.

82. Mao SH, Jiang J, Sun X, et al. Timing of menarche in Chinese girls with and without adolescent idiopathic scoliosis: current results and review of the literature. Eur Spine J 2011;20:260-5.

83. Yim AP, Yeung HY, Hung VW, et al. Abnormal skeletal growth patterns in adolescent idiopathic scolio- 
sis: a longitudinal study until skeletal maturity. Spine (Phila Pa 1976) 2012;37:E1148-54.

84. Janusz P, Kotwicka M, Andrusiewicz M, Czaprowski D, Czubak J, Kotwicki T. Estrogen receptors genes polymorphisms and age at menarche in idiopathic scoliosis. BMC Musculoskelet Disord 2014;15:383.

85. Treloar SA, Martin NG. Age at menarche as a fitness trait: nonadditive genetic variance detected in a large twin sample. Am J Hum Genet 1990;47:137-48.

86. Villamor E, Marin C, Mora-Plazas M, Baylin A. Vitamin $\mathrm{D}$ deficiency and age at menarche: a prospective study. Am J Clin Nutr 2011;94:1020-5.

87. Grivas TB, Vasiliadis E, Mouzakis V, Mihas C, Koufopoulos G. Association between adolescent idiopathic scoliosis prevalence and age at menarche in different geographic latitudes. Scoliosis 2006;1:9.

88. Dossus L, Kvaskoff M, Bijon A, et al. Latitude and ultraviolet radiation dose in the birthplace in relation to menarcheal age in a large cohort of French women. Int J Epidemiol 2013;42:590-600.

89. Sohn K. The influence of climate on age at menarche: augmented with the influence of ancestry. Homo 2016;67:328-36.

90. Hagenau T, Vest R, Gissel TN, et al. Global vitamin $\mathrm{D}$ levels in relation to age, gender, skin pigmentation and latitude: an ecologic meta-regression analysis. Osteoporos Int 2009;20:133-40.

91. Yermachenko A, Dvornyk V. Nongenetic determinants of age at menarche: a systematic review. Biomed Res Int 2014;2014:371583.

92. Lundqvist J. Vitamin D as a regulator of steroidogenic enzymes. F1000Research 2014;3:155. https:// doi.org/10.12688/f1000research.4714.1.

93. Krishnan AV, Swami S, Feldman D. Vitamin D and breast cancer: inhibition of estrogen synthesis and signaling. J Steroid Biochem Mol Biol 2010;121:3438.

94. Yu WS, Chan KY, Yu FW, et al. Bone structural and mechanical indices in adolescent idiopathic scoliosis evaluated by high-resolution peripheral quantitative computed tomography (HR-pQCT). Bone 2014;61:109-15.

95. Cheng JC, Qin L, Cheung CS, et al. Generalized low areal and volumetric bone mineral density in adolescent idiopathic scoliosis. J Bone Miner Res 2000;15:1587-95.

96. Cheung TF, Cheuk KY, Yu FW, et al. Prevalence of vitamin $\mathrm{D}$ insufficiency among adolescents and its correlation with bone parameters using highresolution peripheral quantitative computed tomography. Osteoporos Int 2016;27:2477-88.

97. Burner WL 3rd, Badger VM, Sherman FC. Osteoporosis and acquired back deformities. J Pediatr Orthop 1982;2:383-5.

98. Velis KP, Healey JH, Schneider R. Osteoporosis in unstable adult scoliosis. Clin Orthop Relat Res 1988;(237):132-41.

99. Cheng JC, Guo X. Osteopenia in adolescent idiopathic scoliosis: a primary problem or secondary to the spinal deformity? Spine (Phila Pa 1976) 1997;22:1716-21.

100. Yip BH, Yu FW, Wang Z, et al. Prognostic value of bone mineral density on curve progression: a longitudinal cohort study of 513 girls with adolescent idiopathic scoliosis. Sci Rep 2016;6:39220.

101. Wang ZW, Lee WY, Lam TP, et al. Defining the bone morphometry, micro-architecture and volumetric density profile in osteopenic vs non-osteopenic adolescent idiopathic scoliosis. Eur Spine J 2017;26:1586-94.

102. Tam EM, Yu FW, Hung VW, et al. Are volumetric bone mineral density and bone micro-architecture associated with leptin and soluble leptin receptor levels in adolescent idiopathic scoliosis?: a casecontrol study. PLoS One 2014;9:e87939.

103. Suh KT, Lee SS, Hwang SH, Kim SJ, Lee JS. Elevated soluble receptor activator of nuclear factor-kappaB ligand and reduced bone mineral density in patients with adolescent idiopathic scoliosis. Eur Spine J 2007;16:1563-9.

104. Silva RT, Fernandes RJ, Ono AH, Marcon RM, Cristante AF, de Barros Filho TE. Role of different hormones in the pathogenesis and severity of adolescent idiopathic scoliosis. Acta Ortop Bras 2017;25:15-7.

105. Lehtonen-Veromaa MK, Mottonen TT, Nuotio IO, Irjala KM, Leino AE, Viikari JS. Vitamin D and attainment of peak bone mass among peripubertal Finnish girls: a 3-y prospective study. Am J Clin Nutr 2002;76:1446-53.

106. Zhu K, Oddy WH, Holt P, et al. Tracking of vitamin D status from childhood to early adulthood and its association with peak bone mass. Am J Clin Nutr 2017;106:276-83. 
107. Cashman KD, Hill TR, Cotter AA, et al. Low vitamin D status adversely affects bone health parameters in adolescents. Am J Clin Nutr 2008;87:103944.

108. Sayers A, Fraser WD, Lawlor DA, Tobias JH. 25-Hydroxyvitamin-D3 levels are positively related to subsequent cortical bone development in childhood: findings from a large prospective cohort study. Osteoporos Int 2012;23:2117-28.

109. Fox KM, Magaziner J, Sherwin R, et al. Reproductive correlates of bone mass in elderly women: study of Osteoporotic Fractures Research Group. J Bone Miner Res 1993;8:901-8.

110. Tuppurainen M, Kroger H, Saarikoski S, Honkanen $\mathrm{R}$, Alhava E. The effect of gynecological risk factors on lumbar and femoral bone mineral density in peri- and postmenopausal women. Maturitas 1995;21:137-45.

111. Gerdhem P, Obrant KJ. Bone mineral density in old age: the influence of age at menarche and menopause. J Bone Miner Metab 2004;22:372-5.

112. Apter D, Vihko R. Premenarcheal endocrine changes in relation to age at menarche. Clin Endocrinol (Oxf) 1985;22:753-60.

113. Chang HK, Chang DG, Myong JP, et al. Bone mineral density among Korean females aged 2050 years: influence of age at menarche (The Korea National Health and Nutrition Examination Survey 2008-2011). Osteoporos Int 2017;28:2129-36.

114. Ho AY, Kung AW. Determinants of peak bone mineral density and bone area in young women. J Bone Miner Metab 2005;23:470-5.

115. Chevalley T, Bonjour JP, Ferrari S, Rizzoli R. Influence of age at menarche on forearm bone microstructure in healthy young women. J Clin Endocrinol Metab 2008;93:2594-601.

116. Kulis A, Zarzycki D, Jaśkiewicz J. Concentration of estradiol in girls with idiophatic scoliosis. Ortop Traumatol Rehabil 2006;8:455-9.

117. Esposito T, Uccello R, Caliendo R, et al. Estrogen receptor polymorphism, estrogen content and idiopathic scoliosis in human: a possible genetic linkage. J Steroid Biochem Mol Biol 2009;116:56-60.

118. Man GC, Wong JH, Wang WW, et al. Abnormal melatonin receptor $1 \mathrm{~B}$ expression in osteoblasts from girls with adolescent idiopathic scoliosis. J Pineal Res 2011;50:395-402.
119. Chen C, Xu C, Zhou T, et al. Abnormal osteogenic and chondrogenic differentiation of human mesenchymal stem cells from patients with adolescent idiopathic scoliosis in response to melatonin. Mol Med Rep 2016;14:1201-9.

120. Clark EM, Taylor HJ, Harding I, et al. Association between components of body composition and scoliosis: a prospective cohort study reporting differences identifiable before the onset of scoliosis. J Bone Miner Res 2014;29:1729-36.

121. Burwell RG, Clark EM, Dangerfield PH, Moulton A. Adolescent idiopathic scoliosis (AIS): a multifactorial cascade concept for pathogenesis and embryonic origin. Scoliosis Spinal Disord 2016;11:8.

122. Weinstein SL, Dolan LA, Cheng JC, Danielsson A, Morcuende JA. Adolescent idiopathic scoliosis. Lancet 2008;371:1527-37.

123. Raczkowski JW. The concentrations of testosterone and estradiol in girls with adolescent idiopathic scoliosis. Neuro Endocrinol Lett 2007;28:302-4.

124. Sanders JO, Browne RH, McConnell SJ, Margraf SA, Cooney TE, Finegold DN. Maturity assessment and curve progression in girls with idiopathic scoliosis. J Bone Joint Surg Am 2007;89:64-73.

125. Kulis A, Gozdzialska A, Drąg J, et al. Participation of sex hormones in multifactorial pathogenesis of adolescent idiopathic scoliosis. Int Orthop 2015;39:1227-36.

126. Cutler GB Jr. The role of estrogen in bone growth and maturation during childhood and adolescence. J Steroid Biochem Mol Biol 1997;61:141-4.

127. Letellier K, Azeddine B, Parent S, et al. Estrogen cross-talk with the melatonin signaling pathway in human osteoblasts derived from adolescent idiopathic scoliosis patients. J Pineal Res 2008;45:38393.

128. Del Rio B, Garcia Pedrero JM, Martinez-Campa C, et al. Melatonin, an endogenous-specific inhibitor of estrogen receptor alpha via calmodulin. J Biol Chem 2004;279:38294-302.

129. Sanchez-Barcelo EJ, Mediavilla MD, Tan DX, Reiter RJ. Scientific basis for the potential use of melatonin in bone diseases: osteoporosis and adolescent idiopathic scoliosis. J Osteoporos 2010;2010:830231.

130. Gallagher JC, Riggs BL, DeLuca HF. Effect of estrogen on calcium absorption and serum vitamin $\mathrm{D}$ metabolites in postmenopausal osteoporosis. J Clin 
Endocrinol Metab 1980;51:1359-64.

131. Gilad LA, Bresler T, Gnainsky J, Smirnoff P, Schwartz B. Regulation of vitamin D receptor expression via estrogen-induced activation of the ERK $1 / 2$ signaling pathway in colon and breast cancer cells. J Endocrinol 2005;185:577-92.

132. Davoodi F, Brenner RV, Evans SR, et al. Modulation of vitamin $\mathrm{D}$ receptor and estrogen receptor by 1,25(OH)2-vitamin D3 in T-47D human breast cancer cells. J Steroid Biochem Mol Biol 1995;54:14753.

133. Xu H, Long JR, Li MX, Deng HW. Interaction effects between estrogen receptor alpha and vitamin $\mathrm{D}$ receptor genes on age at menarche in Chinese women. Acta Pharmacol Sin 2005;26:860-4.

134. Willing M, Sowers M, Aron D, et al. Bone mineral density and its change in white women: estrogen and vitamin $\mathrm{D}$ receptor genotypes and their interaction. J Bone Miner Res 1998;13:695-705.

135. Machida M, Murai I, Miyashita Y, Dubousset J, Yamada T, Kimura J. Pathogenesis of idiopathic scoliosis: experimental study in rats. Spine (Phila $\mathrm{Pa}$ 1976) 1999;24:1985-9.

136. Dubousset J, Machida M. Possible role of the pineal gland in the pathogenesis of idiopathic scoliosis: experimental and clinical studies. Bull Acad Natl Med 2001;185:593-602.

137. Brodner W, Krepler P, Nicolakis M, et al. Melatonin and adolescent idiopathic scoliosis. J Bone Joint Surg Br 2000;82:399-403.

138. Cheung KM, Wang T, Poon AM, et al. The effect of pinealectomy on scoliosis development in young nonhuman primates. Spine (Phila Pa 1976) 2005;30:2009-13.

139. Yang S, Zheng C, Jiang J, et al. The value of applying a melatonin antagonist (Luzindole) in improving the success rate of the bipedal rat scoliosis model. BMC Musculoskelet Disord 2017;18:137.

140. Azeddine B, Letellier K, Wang da S, Moldovan F, Moreau A. Molecular determinants of melatonin signaling dysfunction in adolescent idiopathic scoliosis. Clin Orthop Relat Res 2007;462:45-52.

141. Nakade O, Koyama H, Ariji H, Yajima A, Kaku T. Melatonin stimulates proliferation and type I collagen synthesis in human bone cells in vitro. J Pineal Res 1999;27:106-10.

142. Satomura K, Tobiume S, Tokuyama R, et al. Mela- tonin at pharmacological doses enhances human osteoblastic differentiation in vitro and promotes mouse cortical bone formation in vivo. J Pineal Res 2007;42:231-9.

143. Roth JA, Kim BG, Lin WL, Cho MI. Melatonin promotes osteoblast differentiation and bone formation. J Biol Chem 1999;274:22041-7.

144. Feskanich D, Hankinson SE, Schernhammer ES. Nightshift work and fracture risk: the Nurses' Health Study. Osteoporos Int 2009;20:537-42.

145. Reiter RJ, Tan DX, Korkmaz A. The circadian melatonin rhythm and its modulation: possible impact on hypertension. J Hypertens Suppl 2009;27:S17-20.

146. Golan D, Halhal B, Glass-Marmor L, et al. Vitamin D supplementation for patients with multiple sclerosis treated with interferon-beta: a randomized controlled trial assessing the effect on flu-like symptoms and immunomodulatory properties. BMC Neurol 2013;13:60.

147. Brzezinski A. Melatonin in humans. N Engl J Med 1997;336:186-95.

148. Hajimohammadi M, Shab-Bidar S, Neyestani TR. Vitamin D and serum leptin: a systematic review and meta-analysis of observational studies and randomized controlled trials. Eur J Clin Nutr 2017;71:1144-53.

149. Upadhyay J, Farr OM, Mantzoros CS. The role of leptin in regulating bone metabolism. Metabolism 2015;64:105-13.

150. Qiu Y, Sun X, Qiu X, et al. Decreased circulating leptin level and its association with body and bone mass in girls with adolescent idiopathic scoliosis. Spine (Phila Pa 1976) 2007;32:2703-10.

151. Barrios C, Cortes S, Perez-Encinas C, et al. Anthropometry and body composition profile of girls with nonsurgically treated adolescent idiopathic scoliosis. Spine (Phila Pa 1976) 2011;36:1470-7.

152. Takeda S. Leptin and beta-blockers in bone metabolism. Clin Calcium 2004;14:241-7.

153. Thomas T, Gori F, Khosla S, Jensen MD, Burguera B, Riggs BL. Leptin acts on human marrow stromal cells to enhance differentiation to osteoblasts and to inhibit differentiation to adipocytes. Endocrinology 1999;140:1630-8.

154. Holloway WR, Collier FM, Aitken CJ, et al. Leptin inhibits osteoclast generation. J Bone Miner Res 2002;17:200-9. 
155. Matkovic V, Ilich JZ, Skugor M, et al. Leptin is inversely related to age at menarche in human females. J Clin Endocrinol Metab 1997;82:3239-45.

156. Gibson WT, Farooqi IS, Moreau M, et al. Congenital leptin deficiency due to homozygosity for the Delta133G mutation: report of another case and evaluation of response to four years of leptin therapy. J Clin Endocrinol Metab 2004;89:4821-6.

157. Giudici KV PhD, Fisberg RM, Marchioni DML, Peters BSE, Martini LA. Crosstalk between bone and fat tissue: associations between vitamin $\mathrm{D}$, osteocalcin, adipokines, and markers of glucose metabolism among adolescents. J Am Coll Nutr 2017;36:273-80.

158. Menendez C, Lage M, Peino R, et al. Retinoic acid and vitamin $\mathrm{D}(3)$ powerfully inhibit in vitro leptin secretion by human adipose tissue. J Endocrinol 2001;170:425-31.

159. Kim JH, Choi JH. Pathophysiology and clinical characteristics of hypothalamic obesity in children and adolescents. Ann Pediatr Endocrinol Metab 2013;18:161-7.

160. Maetani M, Maskarinec G, Franke AA, Cooney RV. Association of leptin, 25-hydroxyvitamin D, and parathyroid hormone in women. Nutr Cancer 2009;61:225-31.

161. Burwell RG, Dangerfield PH, Moulton A, Grivas TB. Adolescent idiopathic scoliosis (AIS), environment, exposome and epigenetics: a molecular perspective of postnatal normal spinal growth and the etiopathogenesis of AIS with consideration of a network approach and possible implications for medical therapy. Scoliosis 2011;6:26.

162. Wajchenberg M, Martins DE, Lazar M. What is the best way to determine the cause of adolescent idiopathic scoliosis? Ann Transl Med 2015;3:48.

163. Artaza JN, Norris KC. Vitamin D reduces the expression of collagen and key profibrotic factors by inducing an antifibrotic phenotype in mesenchymal multipotent cells. J Endocrinol 2009;200:207-21.

164. Lebel A, Lebel VA. Severe progressive scoliosis in an adult female possibly secondary thoracic surgery in childhood treated with scoliosis specific Schroth physiotherapy: case presentation. Scoliosis Spinal Disord 2016;11(Suppl 2):41.

165. Brooks WJ, Krupinski EA, Hawes MC. Reversal of childhood idiopathic scoliosis in an adult, without surgery: a case report and literature review. Scoliosis
2009;4:27.

166. Guillemant J, Le HT, Maria A, Allemandou A, Peres G, Guillemant S. Wintertime vitamin D deficiency in male adolescents: effect on parathyroid function and response to vitamin D3 supplements. Osteoporos Int 2001;12:875-9.

167. Sullivan SS, Rosen CJ, Halteman WA, Chen TC, Holick MF. Adolescent girls in Maine are at risk for vitamin D insufficiency. J Am Diet Assoc 2005;105:971-4.

168. Rockell JE, Green TJ, Skeaff CM, et al. Season and ethnicity are determinants of serum 25-hydroxyvitamin D concentrations in New Zealand children aged 5-14 y. J Nutr 2005;135:2602-8.

169. Kalkwarf HJ, Khoury JC, Bean J, Elliot JG. Vitamin $\mathrm{K}$, bone turnover, and bone mass in girls. Am J Clin Nutr 2004;80:1075-80.

170. Van Summeren M, Braam L, Noirt F, Kuis W, Vermeer C. Pronounced elevation of undercarboxylated osteocalcin in healthy children. Pediatr Res 2007;61:366-70.

171. Chinda D, Shimoyama T, Iino C, Matsuzaka M, Nakaji S, Fukuda S. Decrease of estradiol and several lifestyle factors, but not helicobacter pylori infection, are significant risks for osteopenia in Japanese females. Digestion 2017;96:103-9.

172. Xiong B, Sevastik JA, Hedlund R, Sevastik B. Radiographic changes at the coronal plane in early scoliosis. Spine (Phila Pa 1976) 1994;19:159-64.

173. Scherrer SA, Begon M, Leardini A, Coillard C, Rivard CH, Allard P. Three-dimensional vertebral wedging in mild and moderate adolescent idiopathic scoliosis. PLoS One 2013;8:e71504.

174. Begon M, Scherrer SA, Coillard C, Rivard CH, Allard P. Three-dimensional vertebral wedging and pelvic asymmetries in the early stages of adolescent idiopathic scoliosis. Spine J 2015;15:477-86.

175. Stokes IA, Aronsson DD. Disc and vertebral wedging in patients with progressive scoliosis. J Spinal Disord 2001;14:317-22.

176. Modi HN, Suh SW, Song HR, Yang JH, Kim HJ, Modi CH. Differential wedging of vertebral body and intervertebral disc in thoracic and lumbar spine in adolescent idiopathic scoliosis: a cross sectional study in 150 patients. Scoliosis 2008;3:11.

177. Will RE, Stokes IA, Qiu X, Walker MR, Sanders JO. Cobb angle progression in adolescent scoliosis be- 
gins at the intervertebral disc. Spine (Phila Pa 1976) 2009;34:2782-6.

178. Taylor TK, Ghosh P, Bushell GR. The contribution of the intervertebral disk to the scoliotic deformity. Clin Orthop Relat Res 1981;(156):79-90.

179. Keenan BE, Izatt MT, Askin GN, et al. Sequential magnetic resonance imaging reveals individual level deformities of vertebrae and discs in the growing scoliotic spine. Spine Deform 2017;5:197-207.

180. Wang S, Qiu Y, Ma W, et al. Comparison of disc and vertebral wedging between patients with adolescent idiopathic scoliosis and Chiari malformation-associated scoliosis. J Spinal Disord Tech 2012;25:27784.

181. Stokes IA. Mechanical modulation of spinal growth and progression of adolescent scoliosis. Stud Health Technol Inform 2008;135:75-83.

182. Stokes IA. Analysis and simulation of progressive adolescent scoliosis by biomechanical growth modulation. Eur Spine J 2007;16:1621-8.

183. Pollintine P, Luo J, Offa-Jones B, Dolan P, Adams
MA. Bone creep can cause progressive vertebral deformity. Bone 2009;45:466-72.

184. Luo J, Pollintine P, Gomm E, Dolan P, Adams MA. Vertebral deformity arising from an accelerated “creep" mechanism. Eur Spine J 2012;21:1684-91.

185. Wren TA, Ponrartana S, Aggabao PC, Poorghasamians E, Gilsanz V. Association between vertebral cross-sectional area and vertebral wedging in children and adolescents: a cross-sectional analysis. J Bone Miner Res 2017;32:2257-62.

186. Wang WJ, Sun C, Liu Z, et al. Transcription factor Runx2 in the low bone mineral density of girls with adolescent idiopathic scoliosis. Orthop Surg 2014;6:8-14.

187. Obarzanek E, Hunsberger SA, Van Horn L, et al. Safety of a fat-reduced diet: the Dietary Intervention Study in Children (DISC). Pediatrics 1997;100:51-9.

188. Obarzanek E, Hunsberger SA, van Horn L, et al. Safety of a fat-reduced diet: the Dietary Intervention Study in Children (DISC). Pediatrics 1997;100:51-9. 